EGU2020-17676

https://doi.org/10.5194/egusphere-egu2020-17676

EGU General Assembly 2020

(c) Author(s) 2020. This work is distributed under

the Creative Commons Attribution 4.0 License.

\title{
Lateral transport of SOC induced by water erosion in a Spanish agroecosystem
}

\author{
Leticia Gaspar ${ }^{1}$, Lionel Mabit ${ }^{2}$, Ivan Lizaga ${ }^{1}$, and Ana Navas ${ }^{1}$ \\ ${ }^{1}$ Soil and Water Department, Estación Experimental de Aula Dei (EEAD-CSIC), Zaragoza, Spain \\ (leticia.gaspar.ferrer@gmail.com) \\ ${ }^{2}$ Soil and Water Management \& Crop Nutrition Laboratory, Joint FAO/IAEA Division of Nuclear Techniques in Food and \\ Agriculture, Department of Nuclear Sciences and Applications, International Atomic Energy Agency, Vienna, Austria
}

The main route for the lateral movement of soil organic carbon (SOC) is water erosion. Awareness of the distribution and magnitude of land carbon mobilization is important both for improving models of the carbon cycle and for management practices aimed to preserve carbon stocks and enhance carbon sinks. There is a need to consider the global significance of soil erosion from soil organic carbon cycling schemes and for this reason, the movement of SOC during erosion processes should be elucidated.

Our study aims to estimate the SOC redistribution induced by water erosion during a 40 years period in an agroforestry mountain ecosystem located in northern Spain. To this purpose, topographically driven transects were selected with mixed land uses to i) assess what factors modify the runoff patterns with impact on soil and carbon redistribution and ii) evaluate the mobilization of topsoil organic carbon along the transects.

The lateral movement of SOC shows similar spatial patterns with that of soil erosion. To identify whether erosional or depositional processes have been predominant in the sampling sites we used ${ }^{137} \mathrm{Cs}$ inventories and the characterization of terrain attributes of the study with a detailed analysis of the main runoff pathways. Results indicate that SOC losses were related to an increase in water flow accumulation, while the highest SOC gains were recorded at concave positions. Soil erosion processes and the content of SOC in soils are the two main factors controlling carbon budgets. The topographical and geomorphological characteristics of the transects, the spatial distribution of land uses and the presence of landscape linear elements such as terraces or paths, affect runoff and determine the sediment connectivity and carbon dynamics along the slopes.

The interactions between topography and land use produce significant positive or negative effects on SOC accumulation, particularly in areas with complex topography, as the results obtained in our study sustain. Even though the effect of topography and land use/land cover and their interactions on the horizontal distributions of carbon remains largely unknown, our approach contributes to better understand the pattern of gains and losses of soil organic and inorganic carbon induced by water erosion. 
